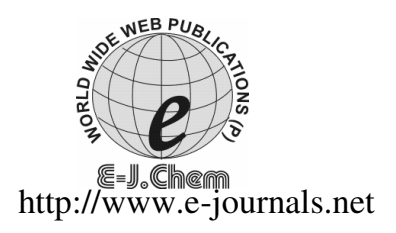

ISSN: 0973-4945; CODEN ECJHAO

E-Journal of Chemistry

2012, 9(1), 83-88

\title{
Determination of $\mathrm{Nd}^{3+}$ Ions in Solution Samples by a Coated Wire Ion-Selective Sensor
}

\author{
HASSAN ALI ZAMANI \\ Department of Applied Chemistry \\ Quchan branch, Islamic Azad University, Quchan, Iran \\ haszamani@yahoo.com
}

Received 1 May 2011; Accepted 14 July 2011

\begin{abstract}
A new coated wire electrode (CWE) using 5-(methylsulfanyl)-3phenyl-1H-1,2,4-triazole (MPT) as an ionophore has been developed as a neodymium ion-selective sensor. The sensor exhibits Nernstian response for the $\mathrm{Nd}^{3+}$ ions in the concentration range of $1.0 \times 10^{-6}-1.0 \times 10^{-2} \mathrm{M}$ with detection limit of $3.7 \times 10^{-7}$ M. It displays a Nernstian slope of $20.2 \pm 0.2 \mathrm{mV} /$ decade in the $\mathrm{pH}$ range of 2.7-8.1. The proposed sensor also exhibits a fast response time of $\sim 5 \mathrm{~s}$. The sensor revealed high selectivity with respect to all common alkali, alkaline earth, transition and heavy metal ions, including members of the lanthanide family other than $\mathrm{Nd}^{3+}$. The electrode was used as an indicator electrode in the potentiometric titration of $\mathrm{Nd}(\mathrm{III})$ ions with EDTA. The electrode was also employed for the determination of the $\mathrm{Nd}^{3+}$ ions concentration in water solution samples.
\end{abstract}

Keywords: Coated wire electrode, Ion-selective electrode, PVC membrane, Sensor, Potentiometry

\section{Introduction}

Neodymium is used in polymer catalyst, lasers, dielectrics and coloring glasses, able to adsorb the yellow sodium glare of the flame. Regarding neodymium salts, they are used as colourants for enamels and in powerful permanent magnets such as $\mathrm{Nd}_{2} \mathrm{Fe}_{14} \mathrm{~B}^{1}$. Different instrumental methods have been reported for determination of neodymium including inductively coupled plasma mass spectroscopy (ICP-MS) and ICP. Although these techniques provide an accurate measurement in trace amount of elements, they destroyed the samples. In comparison, potentiometric ion selective sensors offer advantages of low cost, portability, selectivity and simple operatory. They also provide an analysis method without destruction of sample ${ }^{2-10}$. To the best of our knowledge there is no report on a carrier-based ion-selective membrane coated on wire electrode for $\mathrm{Nd}$ (III) ion. We have recently reported a number of sensors for some transition metal ions ${ }^{11-31}$. The aim of this work is the fabrication 
of a $\mathrm{Nd}^{3+}$-coated wire PVC membrane ion selective electrode based on 5-(methylsulfanyl)-3phenyl-1H-1,2,4-triazole (MPT) (Figure 1) as a suitable ion carrier for the selective and sensitive potentiometric determination of $\mathrm{Nd}(\mathrm{III})$ ion across a broad concentration range.

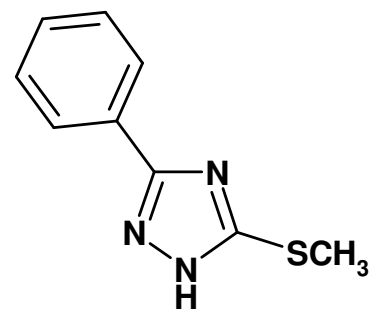

\section{Experimental}

Figure 1. The MPT structure

Reagent grades benzyl acetate (BA), nitrobenzene (NB), dibutyl phthalate (DBP), acetophenone (AP), sodium tetraphenyl borate (NaTPB), tetrahydrofuran (THF) and relatively high molecular weight PVC. All reagents were used without any modification. The ionophore 5-(methylsulfanyl)-3-phenyl-1H-1,2,4-triazole (MPT) was prepared as formerly described ${ }^{32}$. As far as the nitrate and chloride salts of all employed cations are concerned, they were of the highest available purity and were $\mathrm{P}_{2} \mathrm{O}_{5}$-vacuum dried. During the experiments, triply distilled deionized water was used.

\section{CWE electrode preparation}

The required amounts of the membrane ingredients $(30 \mathrm{mg}$ powdered PVC, $2 \mathrm{mg}$ ionophore MPT, $2 \mathrm{mg}$ anion excluder NaTPB and $66 \mathrm{mg}$ NB as plasticizer) were mixed and dissolved in $5 \mathrm{~mL}$ of THF. The resulting mixture was transferred into a glass dish of $2 \mathrm{~cm}$ in diameter. The THF content of the mixture was evaporated slowly, until an oily concentrated mixture was obtained. Copper wire, about $1 \mathrm{~mm}$ diameter and $10 \mathrm{~mm}$ length, sealed into end of a glass tube and soldered onto a shielded cable, was cleaned using nitric acid. The wire was then coated by repeated dipping (about five times, a few minutes between dips) into the membrane solution. A membrane was formed on the copper surface, which was allowed to dry overnight ${ }^{33-39}$. The electrode was conditioned with $0.01 \mathrm{M} \mathrm{NdCl}_{3}$ for $24 \mathrm{~h}$.

\section{The EMF measurements}

All emf measurements were carried out with the following assembly; CWEltest solution|Reference electrode. A Corning ion analyzer $250 \mathrm{pH} / \mathrm{mV}$ meter was used for the potential measurements at $25.0 \pm 0.1{ }^{0} \mathrm{C}$. The activities were calculated according to the Debye-Huckel procedure ${ }^{40}$.

\section{Results and Discussion}

\section{Potential response of the electrode}

In primary experiments, MPT was used as a neutral ionophore to prepare PVC membrane ion-selective coated on coated wire electrodes for a wide variety of cations, including alkali, alkaline earth, transition and heavy metal ions. Among different cations tested, $\mathrm{Nd}^{3+}$ ion illustrated a strong response to the PVC membrane based on MPT. This is most probably due to the specific interaction of MPT and $\mathrm{Nd}^{3+}$ ions and the rapid exchange kinetics of the resulting MPT $-\mathrm{Nd}^{3+}$ complex. 


\section{Effect of membrane composition}

The different aspects (such as the properties of the plasticizer (BA, DBP, AP and NB, the plasticizer/PVC ratio, the nature and amount of ionophore MPT and especially, the nature and amount of the additives used (NaTPB) $)^{41-45}$ of the preparation of a $\mathrm{Nd}^{3+}$-selective membrane based on MPT were optimized. Among the four tried plasticizers, NB offers the best sensitivity. Also, MPT amount increase up to the value of $2 \%$ in the membrane resulted in nernstian slope. A maximum slope of $20.2 \pm 0.2 \mathrm{mV} /$ decade of neodymium concentration was observed with $2 \%$ of MPT. lipophilic anions in the composition of cationic-selective membrane sensors not only diminishes the ohmic resistance and enhances the potential behavior and selectivity, but also in poor extraction capacities, increases the sensitivity of the membrane electrodes. ${ }^{45-49}$ However, the membranes with a composition of $30 \%$ PVC, $2 \%$ MPT, $2 \%$ NaTPB and 66\% NB illustrate a nernstian potential response.

\section{Calibration curve}

The electrode shows a linear response to the concentration of $\mathrm{Nd}(\mathrm{III})$ ions in the range of $1.0 \times 10^{-6}$ to $1.0 \times 10^{-2} \mathrm{M}$ (Figure 2). The slope of calibration graph was $20.2 \pm 0.2 \mathrm{mV}$ per decade. The limit of detection, as determined from the intersection of the two extrapolated segments of the calibration graph, was $3.7 \times 10^{-7} \mathrm{M}$.

\section{pH Effect}

The $\mathrm{pH}$ influence of the test solution $\left(1.0 \times 10^{-3} \mathrm{M}\right)$ on the potential response of the membrane sensor was tested in the $\mathrm{pH}$ range of 2.0-11.0. These results are depicted in Figure 3. Obviously, potential remains constant over a $\mathrm{pH}$ range of 2.7-8.1, beyond which the potential changes considerably. The observed drift at higher $\mathrm{pH}$ values could be due to the formation of some hydroxyl complexes of $\mathrm{Nd}^{3+}$ ions in solution. The observed potential increase at low $\mathrm{pH}$ values indicates that the protonated ionophore possesses a poor response to $\mathrm{Nd}^{3+}$ ions and strong response to the $\mathrm{H}_{3} \mathrm{O}^{+}$in solution.

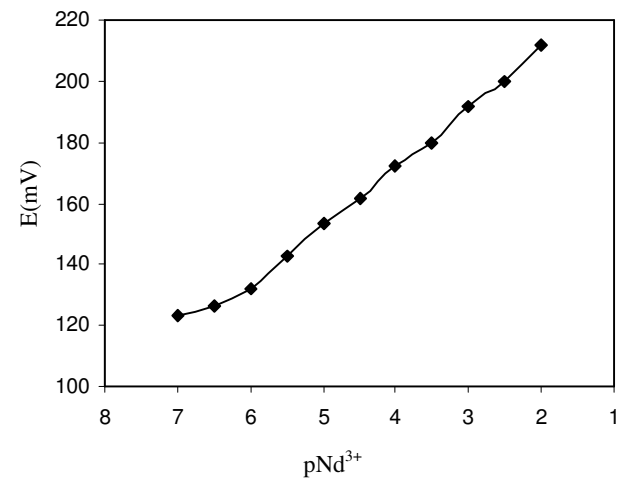

Figure 2. Calibration curve of neodymium electrode based on MPT

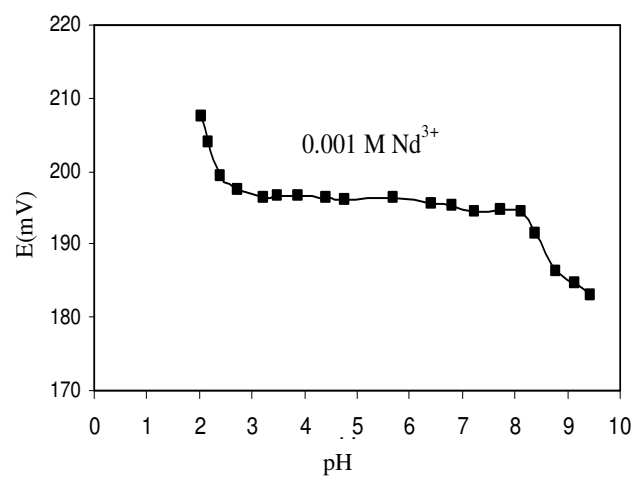

Figure 3. The $\mathrm{pH}$ effect of the test solution on the potential response of the neodymium sensor

\section{Dynamic response time}

The average time required for the $\mathrm{Nd}$ (III) sensor to reach a potential within $\pm 1 \mathrm{mV}$ of the final equilibrium value after successive immersion of a series of $\mathrm{Nd}(\mathrm{III})$ ion solutions, each having a 10-fold difference in concentration, was measured. The static response time of the membrane electrode thus obtained was $\sim 5 \mathrm{~s}$ over the entire concentration range. 


\section{Selectivity of the sensor}

The most important characteristic of any polymeric membrane sensor, is its relative response for the primary ion over other ions present (as interfering foreign cations) in the solution, which is expressed in terms of potentiometric selectivity coefficients. In this work, we determined selectivity coefficients with matched potential method (MPM) ${ }^{50,51}$. The matched potential method selectivity coefficient, $K^{\mathrm{MPM}}$, is then given by the resulting primary ion to interfering ion activity (concentration) ratio, $K^{\mathrm{MPM}}=\Delta a_{\mathrm{A}} / a_{\mathrm{B}}$. The resulting selectivity coefficients values are summarized in Table 1 . The data given in this Table present that the selectivity coefficients of the proposed $\mathrm{Nd}(\mathrm{III})$ membrane sensor were $5.6 \times 10^{-3}$ or smaller, disclosing that this certain sensor is greatly selective in reference with most of the transition and heavy metal ions. The surprisingly high selectivity of the membrane electrode for neodymium ions over the other used cations, most probably arises from the strong tendency of the carrier molecules for neodymium ions.

Table 2. Selectivity coefficients of various interfering ions

\begin{tabular}{|c|c|c|c|}
\hline $\begin{array}{c}\text { Interfering } \\
\text { ions }\end{array}$ & $K_{N^{3+}{ }^{3+}}^{M P M}$ & $\begin{array}{c}\text { Interfering } \\
\text { ions }\end{array}$ & $K_{N d^{3+}{ }^{3+}}^{M P M}$ \\
\hline $\mathrm{Sm}^{3+}$ & $5.6 \times 10^{-3}$ & $\mathrm{Fe}^{3+}$ & $2.8 \times 10^{-3}$ \\
\hline $\mathrm{Ho}^{3+}$ & $6.8 \times 10^{-4}$ & $\mathrm{Cr}^{3+}$ & $4.1 \times 10^{-3}$ \\
\hline $\mathrm{Lu}^{3+}$ & $8.6 \times 10^{-4}$ & $\mathrm{~K}^{+}$ & $8.7 \times 10^{-4}$ \\
\hline $\mathrm{La}^{3+}$ & $7.5 \times 10^{-4}$ & $\mathrm{Na}^{+}$ & $2.2 \times 10^{-3}$ \\
\hline $\mathrm{Dy}^{3+}$ & $6.3 \times 10^{-4}$ & $\mathrm{Ca}^{2+}$ & $8.9 \times 10^{-4}$ \\
\hline $\mathrm{Tb}^{3+}$ & $4.2 \times 10^{-3}$ & $\mathrm{Co}^{2+}$ & $5.3 \times 10^{-3}$ \\
\hline $\operatorname{Pr}^{3+}$ & $3.7 \times 10^{-3}$ & $\mathrm{Ni}^{2+}$ & $3.6 \times 10^{-3}$ \\
\hline $\mathrm{Er}^{3+}$ & $2.4 \times 10^{-3}$ & $\mathrm{~Pb}^{2+}$ & $8.4 \times 10^{-4}$ \\
\hline
\end{tabular}

\section{Analytical applications}

The Nd(III) sensor was successfully used as an indicator electrode in the titration of $20.0 \mathrm{~mL}$ of a $1.0 \times 10^{-4} \mathrm{Nd}^{3+}$ solution with a $1.0 \times 10^{-2} \mathrm{M}$ EDTA. The resulting titration curve is given in Figure 4, demonstrating that the amount of $\mathrm{Nd}$ (III) ion in the solution can be determined with the electrode.

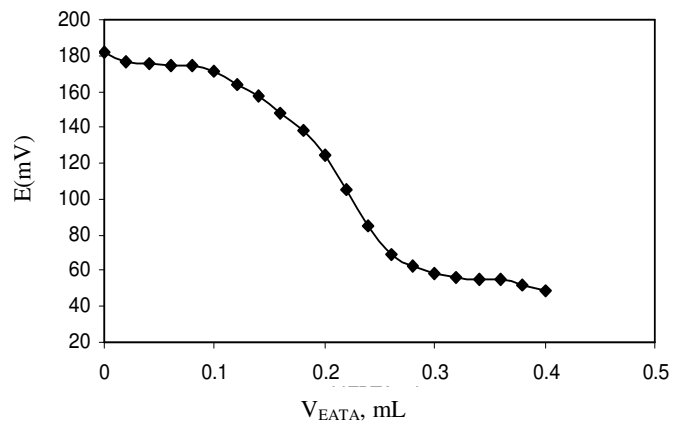

Figure 4. Potential titration curve of $20.0 \mathrm{~mL}$ from a $1.0 \times 10^{-4} \mathrm{M} \mathrm{Nd}^{3+}$ solution with $1.0 \times 10^{-2} \mathrm{M}$ of EDTA.

The proposed sensor was also successfully applied to the determination of $\mathrm{Nd}^{3+}$ ions in tap and river water samples and the results are summarized in Table 2. It was found that the accuracy of neodymium detection in different solution samples is almost quantitative. 
Table 2. Determination of $\mathrm{Nd}^{3+}$ ions in tap water and river water samples with the use of the recommended electrode

\begin{tabular}{cccc}
\hline Sample & Added, $\mathrm{mg} / \mathrm{mL}$ & Found $^{\mathrm{a}}, \mathrm{mg} / \mathrm{mL}$ & Recovery, \% \\
\hline \multirow{3}{*}{ River water } & 0.25 & $0.27 \pm 0.04$ & 112 \\
& 0.50 & $0.55 \pm 0.02$ & 108 \\
Tap water & 0.25 & $0.28 \pm 0.03$ & 116 \\
\hline
\end{tabular}

${ }^{a}$ Results are based on three replicate measurements

\section{Conclusion}

This research demonstrated that constructed coated wire electrode based on 5-(methylsulfanyl)-3phenyl-1H-1,2,4-triazole (MPT) exhibits neodymium selectivity, with very low interference from common alkali, alkaline earth, transition and heavy metal ions. The proposed sensor has a very response time (about $5 \mathrm{~s}$ ) and its potential responses are independent of $\mathrm{pH}$ in the range 2.7-801. The sensor showed a nernstian response (slope of $20.2 \pm 0.2 \mathrm{mV} /$ decade), low limit of detection $\left(3.7 \times 10^{-7} \mathrm{M}\right)$ and wide linear range $\left(1.0 \times 10^{-6}-1.0 \times 10^{-2} \mathrm{M}\right)$ and very low interference from common alkali, alkaline earth, transition and heavy metal ions. It was useed for the determination of the $\mathrm{Nd}(\mathrm{III})$ ions in different solution samples.

\section{Acknowledgment}

The authors gratefully acknowledge the financial support of this research proposal, provided by the Research Council of the Quchan Islamic Azad University.

\section{References}

1. Kirk O R and Othmer F D, Encyclopedia of Chemical Technology' Vol. 19, Wiley, New York p. 851, 1982.

2. Zamani H A, Rohani M, Zangeneh-Asadabadi A, Zabihi M S, Ganjali M R and Salavati-Niasari M, Mater Sci Eng C, 2010, 30, 917.

3. Zamani H A, Rajabzadeh G and Ganjali M R, Sensor Lett., 2009, 7, 114.

4. Mahajan R K, Kaur I and Kumar M, Sens Actuators B, 2003, 91, 26.

5. Zamani H A, Anal. Lett., 2009, 42, 615.

6. Zamani H A, Abedi MR and Ganjali M R, J Chil Chem Soc., 2009, 54, 186.

7. Zamani H A, Ganjali M R, Norouzi P and Adib M, Mater Sci Eng C, 2008, 28, 157.

8. Ganjali M R, Rasoolipour S, Rezapour M, Norouzi P, Amirnasr M and Meghdadi S, Sens Actuators B, 2006, 119, 89.

9. Naddaf E and Zamani H A, Anal Lett., 2009, 42, 2838.

10. Zamani H A, Ganjali M R and Seifi N, Collect Czech Chem Commun., 2007, 72, 1189.

11. Zamani H A, Arvinfar A, Rahimi F, Imani A, Ganjali M R and Meghdadi S, Mater Sci Eng C, 2011, 31, 307.

12. Zamani H A, Nekoei M, Mohammadhosseini M and Ganjali M R, Mater Sci Eng C, 2010, 30, 480 .

13. Zamani H A, Ganjali M R, Norouzi P and Adib M, Aceedy M, Anal Sci., 2006, 22, 943.

14. Masrournia M, Zamani H A, Mirrashid H A, Ganjali M R and Faridbod F, Mater Sci Eng C, 2011, 31, 574.

15. Zamani H A, Imani A, Arvinfar A, Rahimi F, Ganjali M R, Faridbod F and Meghdadi S, Mater Sci Eng C, 2011, 31, 588.

16. Zamani H A, Feizyzadeh B, Faridbod F and Ganjali M R, Sensor Lett., 2011, 9, 1767. 
17. Zamani H A, Rohani M, Mohammadhosseini M, Ganjali M R, Faridbod F and Meghdadi S, Sensor Lett., 2011, 9, 1745

18. Zamani H A, Ganjali M R, Norouzi P, Tadjarodi A and Shahsavani E, Mater Sci Eng C, 2008, 28, 1489.

19. Zamani H A, Rajabzadeh G and Ganjali M R, J Braz Chem Soc., 2006, 17, 1297.

20. Zamani H A, Rajabzadeh G, Masrornia M, Dejbord A, Ganjali M R and Seifi N, Desalination, 2009, 249, 560.

21. Zamani H A, Hamed-Mosavian M T, Aminzadeh E, Ganjali M R, Ghaemy M, Behmadi H and Faridbod F, Desalination, 2010, 250, 56.

22. Ganjali M R, Norouzi P, Adib M and Ahmadalinezhad A, Anal Lett., 2006, 39, 1075.

23. Zamani H A, Masrournia M, Rostame-Faroge M, Ganjali M R and Behmadi H, Sensor Lett., 2008, 6, 759.

24. Zamani H A, Mohammadhossieni M, Nekoei M and Ganjali M R, Sensor Lett., 2010, 8, 303.

25. Zamani H A, Anal Lett., 2008, 41, 1850.

26. Ganjali M R, Rasoolipour S, Rezapour M, Norouzi P, Amirnasr M and Meghdadi S, $J$ Braz Chem Soc., 2006, 17, 1211.

27. Zamani H A, Ganjali M R, Behmadi H and Behnajady M A, Mater Sci Eng C., 2009, 29, 1535.

28. Zamani H A, Masrournia M, Sahebnasagh S and Ganjali M R, Anal Lett., 2009, 42, 555.

29. Zamani H A, Ganjali M R, Norouzi P and Meghdadi S, Anal Lett., 2008, 41, 902.

30. Nekoei M, Zamani H A and Mohammadhossieni M, Anal Lett., 2009, 42, 284.

31. Mohammadhossieni M, Zamani H A and Nekoei M, Anal Lett., 2009, 42, 298.

32. Hoggarth E, J Chem Soc., 1949, 1163.

33. Abedi M R, Zamani H A, Ganjali M R and Norouzi P, Sensor Lett., 2007, 5, 516.

34. Zamani M A, Ganjali M R, Norouzi P and Meghdadi S, J Appl Electrochem., 2007, 37, 853.

35. Behmadi H, Zamani H A, Ganjali M R and Norouzi P, Electrochim Acta., 2007, 53, 1870.

36. Zamani H A, Zabihi M S, Rohani M, Zangeneh-Asadabadi A, Ganjali M A, Faridbod F and Meghdadi S, Mater Sci Eng C, 2011, 31, 409.

37. Mashhadizadeh M H, Mostafavi A, Allah-Abadi H and Sheikhshoai I, Sens Actuators $B, 2006,113,930$.

38. Jain A K, Singh A K, Mehtab S and Saxena P, Anal Chim Acta, 2005, 551, 45.

39. Liu L, Wang L, Yin H, Li Y and He X, Anal Lett., 2006, 39, 879.

40. Kamata S, Bhale A, Fukunaga Y and Murata A, Anal Chem., 1988, 60, 2464.

41. Rosatzin T, Bakker E, Suzuki Y and Simon W, Anal Chim Acta., 1993, 280, 197.

42. Zamani H A, Rajabzadeh G and Ganjali m R, Talanta, 2007, 72, 1093.

43. Abedi M R and Zamani H A, Anal Lett., 2008, 41, 2251.

44. Zamani H A, Rajabzadeh G, Firouz A and Ganjali M R, J Anal Chem., 2007, 62, 1080.

45. Ammann E, Pretsch E, Simon W, Lindner E, Bezegh A and Pungor E, Anal Chim Acta, 1985, 171, 119.

46. Zamani H A, Rajabzadeh G, Ganjali M R and Norouzi P, Anal Chim Acta, 2007, 598, 51.

47. Zamani H A, Ganjali M R, Norouzi P and Adib M, Sensor Lett., 2007, 5, 522

48. Pooyamanesh M J, Zamani H A, Rajabzadeh G, Ganjali M R and Norouzi P, Anal Lett., 2007, 40, 1596.

49. Bakker E, Bühlmann P and Pretsch E, Chem Rev., 1997, 97, 3083.

50. Umezawa Y, Buhlmann P, Umezawa K, Tohda K and Amemiya S, Pure Appl Chem., 2000, 72, 1851.

51. Abedi M R, Zamani H A, Ganjali M R and Norouzi P, Intern J Environ Anal Chem., 2008, 88, 353. 


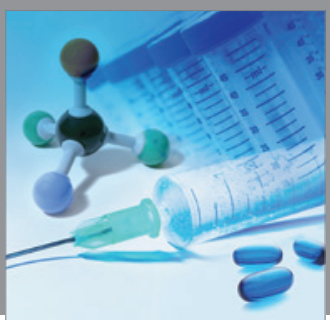

International Journal of

Medicinal Chemistry

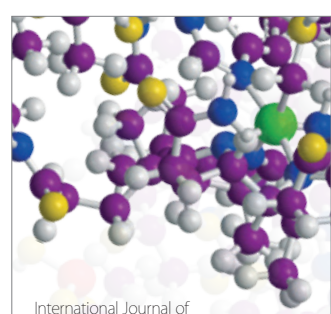

Carbohydrate Chemistry

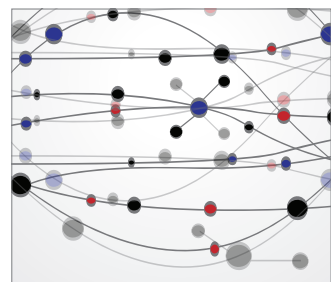

The Scientific World Journal
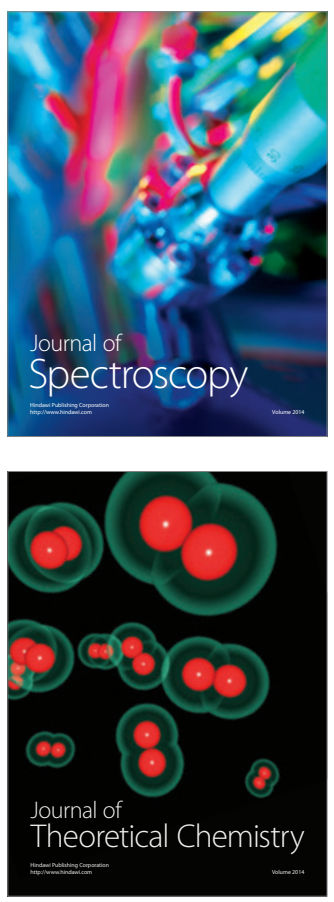
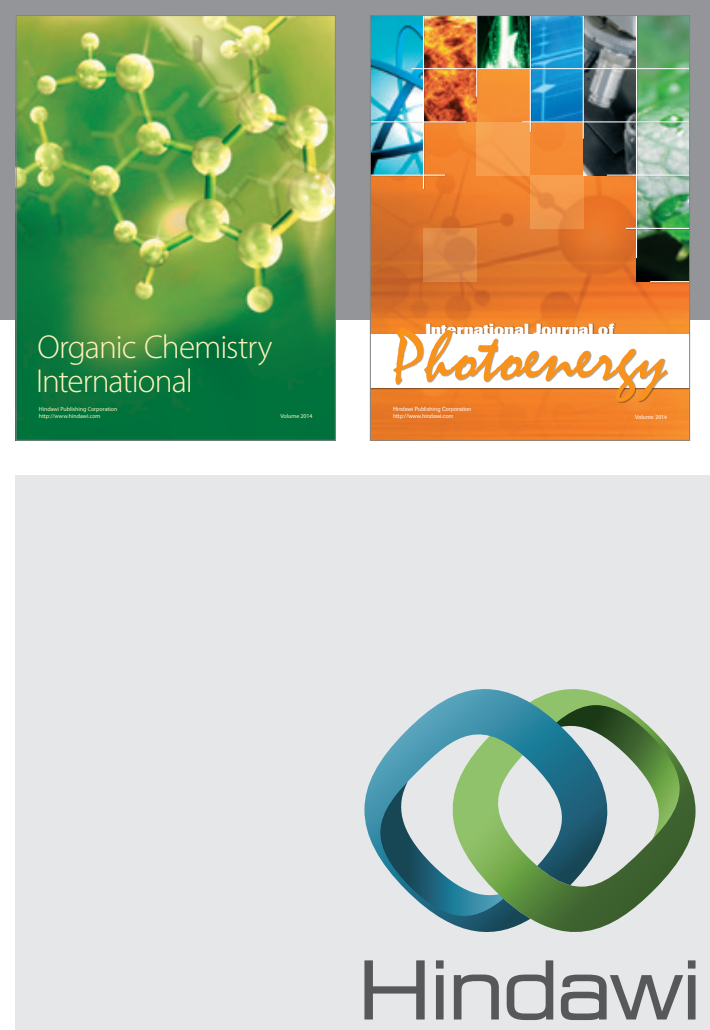

Submit your manuscripts at

http://www.hindawi.com
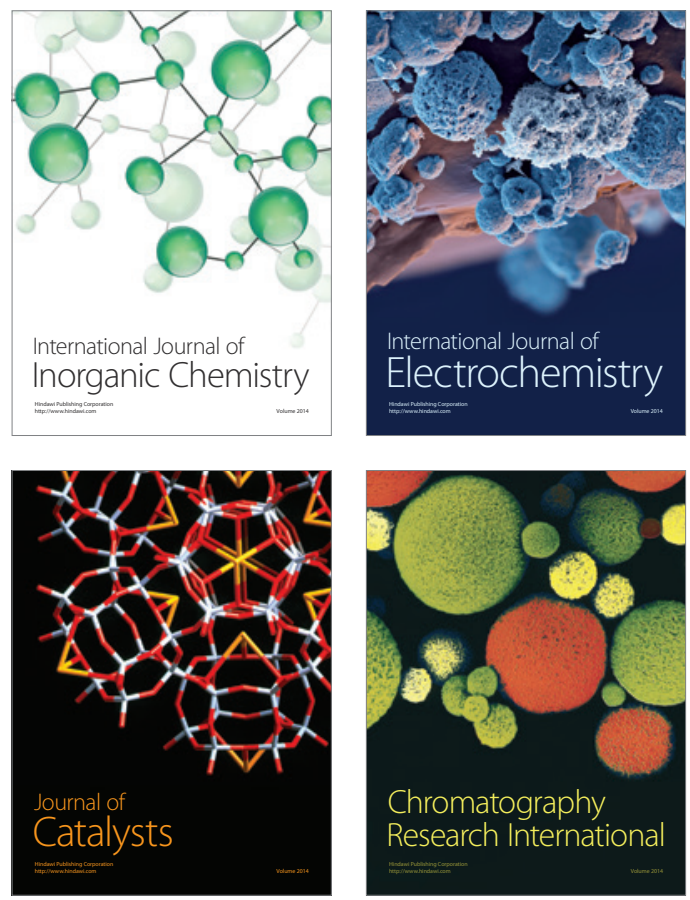
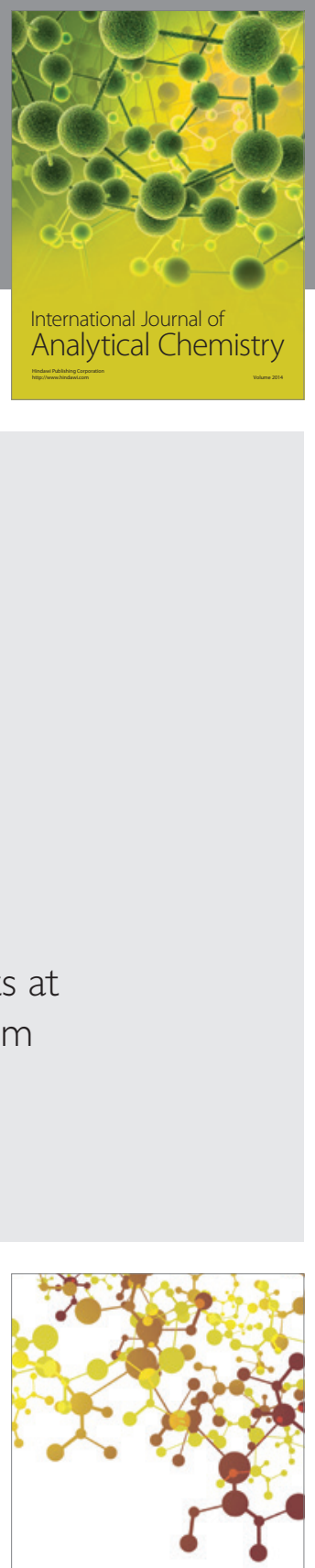

Journal of

Applied Chemistry
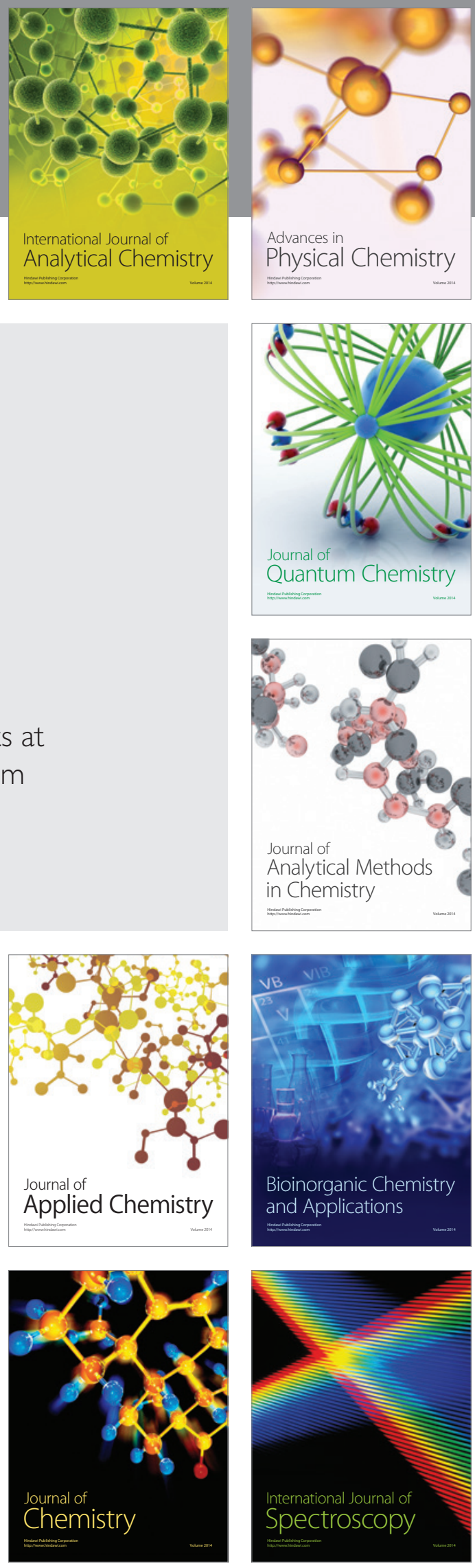